\begin{tabular}{ccc}
\hline ManAGEMENT ISSUES IN & INDUSTRIAL \\
HEALTHCARE SYSTEM & MANAGEMENT \\
\hline
\end{tabular}

\title{
Innovation in public healthcare systems: Do we really understand its potential
}

\author{
Dinesh K. Arya \\ Department of Health, Chief Medical Officer, Northern Territory Government, Australia
}

\begin{abstract}
Keywords:

Innovation, Health,

Healthcare, Health Services

Correspondence:

Dinesh.Arya@nt.gov.au

This paper explores the concept of innovation and evaluates its relevance to public healthcare services. A comprehensive review of innovation in public healthcare systems was done to identify a source of analysis or commentary. This was done with the intention of exploring important considerations in relation to the progress of innovation within public health services. There are a number of factors in the public healthcare systems that need some tough challenges in implementing innovation; however, the environment is ripe for public health services to implement innovation. Various considerations and strategies for enabling public healthcare organizations and implementing innovation were identified.
\end{abstract}

(C)AIMI Journals

\section{Introduction}

Innovation has been a buzz word in manufacturing industries for a long time. In a competitive market, constantly changing and unpredictable market, it is not difficult to comprehend that organizations need to constantly adapt, change, and innovate for their survival. Innovation has been suggested as a critical ingredient to improve performance, gain the competitive advantage, attract new customers, meet customers' expectations, and increase productivity (Zaltman, Duncan, \& Holbek, 1973). Over the last two centuries, health care systems have also evolved. Life expectancy has been developed and quality of life has much improved (Varkey, Horne, \& Bennet, 2008). Diagnostic tools and treatment options have improved considerably and there is greater certainty when reaching home after a stay in hospital. Therefore, healthcare systems have also become more efficient. Apart from the flow of this incremental improvement, there have been a number of innovations. Digitalization of healthcare 
information has helped improve their access to critical information. Healthcare systems have also benefited from innovations in genetics, biotechnology, nanotechnology, and the use of semiconductors, which have helped improve efficacy of treatment, instrumentation, drug delivery, and healthcare processes. Although, the healthcare sector has certainly made a lot of incremental improvements, it still lags behind other industries in terms of encouraging, supporting, and implementing innovations.

\section{Definition of Innovation}

In simple terms, organizational innovation is the creation of valuable and useful new products/services within an organizational context (Woodman, Sawyer, \& Griffin, 1993) and the successful implementation of creative ideas within an organization (Amabile, 1983, 1998; Amabile, Conti, Coon, Lazenby, \& Herron, 1996). More broadly speaking, bringing about a transformational change, reinventing the production line, and implementing a novel way of delivering a product or service are considered as innovation. Innovations are intentionally introduced and are designed to bring significant improvements or benefits. Lansisalmi, Kivimaki, Aalto, and Ruoranen (2006) suggested three main characteristics of innovation including novelty, application component, and intended benefit. These three components are also included in definition of innovation which suggested by West (1990) who defined innovation as the intentional introduction and application within a role, group, or organization, processes, products or procedures. The concept of innovation perceived to be new by the relevant unit of adoption which designed to significantly benefit the individual, organization, group, and other wider society. Innovation in the public sector context should be defined as the creation and implementation of new processes, products, services, and methods of delivery which result in significant improvements in the efficiency, effectiveness, and quality of outcomes. In short, innovation is the application of new ideas to produce better outcomes. However, in the context of public health services, it is also important to be sure that the need to do so efficiently and effectively does not overlook because it is considered as a determinant factor in sustaining the introduction of innovation. When scoping an innovation growth program, it is also important to define innovation as something that is occurring in the present but for future use. The successful innovations of yesterday may be a routine practice today, and are likely to be at increased risk of extinction tomorrow. For example, supply chain innovations may have been the focus of innovation in the industrial and information age. The innovation age has required a paradigm shift that includes demand-side innovation policies to meet the customers' changing needs (Davenport, Leibold, \& Voelpel, 2006). In public healthcare services, the need for bureaucracy seems to be common for glory of innovation in the past to continue to be rebadged as innovation, even though the world has moved towards new ways of doing things.

\section{Types of Innovations}

Innovation is a broad concept which encompasses a wide range of activities and processes. Four types of innovations were proposed by Oslo Manual that encompasses a wide range of changes in firms' activities including product, process, organizational, and marketing innovations.

Product innovation defined as an introduction for a new or significantly improved product or service. These improvements may be related to the technical specifications, components and materials, incorporated software or equipments, techniques, user friendliness, and delivery methods. Process innovation refers to the improvement and introduction of new improved production or delivery method. These improvements encompass some efficient techniques, equipments, and software. On the other hand, organizational innovation refers to the new organizational methods in 
new business practices, workplace organizations, and external relations. Finally, marketing innovation involves new marketing methods, significant changes in product design or packaging, products replacement, and price promotion of existing or new products. Innovation can be in the manner in which people, organizations, companies, entrepreneurs, and even society in itself, create value through exploring the new changes (Christenson, Anthony, \& Roth, 2004; Coelho \& Matias, 2010). Indeed, an innovation would no longer be considered worthwhile if it did not create new values. The Advisory Committee on Measuring Innovation in the 21st Century Economy (2007) defined different types of innovation based on their designs, inventions, development and/or implementation of new or altered products, services, processes, systems, organizational structures, business models for the purpose of creating new or better values for customers, and financial returns for the firm. Furthermore, innovation can be categorized into two groups, namely non-disruptive or disruptive. Non-disruptive innovation refers to the improvement in existing systems, processes, products, and services (Moore, 2004). These improvements have incremental (Hamel, 2000), evolutionary, linear (Hamel, 2000), sustaining. In this way, these are no difference in improvements that the organizations implement to ensure that it is keeping pace with the current norms, standards, and changing expectations. Non-disruptive innovation consists of opportunities which offered by developing and improving other technological systems to make accommodations and meet changing expectations. Disruptive innovation not only introduces newness in content, but also has the potential to deliver exponential change. These are also referred to as radical (Hage \& Hollingsworth, 2000; Harvard Business Essentials, 2003), revolutionary, transformational, and nonlinear (Hamel, 2000). Introduction of new techniques and equipments may lead to change in stakeholders' behavior and transform of old systems. It can also bring about a change in competition which then requires the market to respond accordingly.

\section{Some Prerequisites for Innovation}

There are a number of pre-requisites for innovation. To do things differently, there is a need to have a desire and willingness and of course the innovator or innovating organization needs to have the technical expertise, confidence, and an appetite to take the risk of doing something different. In the private sector, an important goal of a company or business is survival. In a competitive environment, where survival is at stake, a way of gaining a competitive advantage is innovation (Sumii, 1986). It is acknowledged that competition stimulates innovation (Fagerberg, Mowery, \& Nelson, 2005), whether it is in sales, market share, productivity, and efficiency. In the public sector environment (e.g. healthcare system), a key motive of innovation is to take advantage of investment of public funds. This often means responding innovatively, effectively, and efficiently to changes in the environment, government, and community expectations. Knowing that many public sector initiatives require crosssector and across-government innovation, there is also a need to coordinate approaches to deal with emerging issues. In addition to dealing with complex health policy challenges like ageing of population due to change in demographics, cost of new technologies, changing consumer expectations, and emerging lifestyle-related health problems such as smoking, obesity, alcoholism there have been plenty of motives in public health services to stimulate innovation. In fact public health service has to be one sector that is absolutely ripe for innovation. The huge proportion of Gross Domestic Product (GDP) invested in health care and a proportion of budget devoted to public health care by the Commonwealth as well as all State and Territory governments, is not only substantial, but also increasing. The costs of healthcare provision are always estimated high on the political agenda. In the public healthcare system, there are also some serious reasons to improve and innovate including 
the fact that the public healthcare system is profoundly inefficient, it is often plagued by long waiting lists, rate of errors, omissions, post-intervention complications, and rates of hospital acquired infections which remains also unacceptably high ( McGlynn et al., 2003). Fortunately, healthcare system contains some multidisciplinary teams which attract smart people who are driven by strong desire to excel, serve, grow, and deliver. There is an opportunity for highly skilled people from almost every technical expertise - from clinical, administration, business management, customer care, policy, planning, engineering, human resources, and financial management - to come together and deliver. Instead of waiting for all the ducks lining up to create an environment that should enforce innovation, the public healthcare sector struggles to innovate. Some would suggest that it even struggles to take advantage of innovations occurring in other different sectors. Stark examples include delays in implementing appropriate information technology advancements in public healthcare systems, despite availability of these solutions in other industries. Other sectors have been quick to identify its potential, decide to make early investment, and have not only implemented but benefitted of quickly incorporating advancements through technological solutions. It is the most pessimistic ones who think that whereas other industries have completely transformed their business processes, access arrangements, and security systems, healthcare system has been too slow in making the necessary adaptations and changes. As waiting lists are getting longer, health care systems remain fragmented and inefficiencies within the system seem to be increasing with even greater proportion of the healthcare budget to be invested in support systems rather than clinical care centers. Although we want to have a patient-centered healthcare system, we have run our hospitals differently. It means that the talk of supply not keeping pace with the demand which considered as a threat for healthcare system. It is not mean that there have been no innovations in healthcare. Indeed, there have been hundreds of technical advancements in all introduced specialties, new equipment procedures, and techniques. These include electronic health records, technological advances in diagnosis and treatment including vaccines, drugs, technologically sophisticated equipment to treat diseases and improve communication, use of robots in rehabilitation therapy, video scopes (including endoscopes), da Vinci surgical system that allows surgical procedures through robotic hands, and the use of cyber knife to deliver high doses beams of radiation with extreme accuracy. However, objective analysis would suggest that even these technical advancements have occurred in isolated pockets and taken an incredibly long time to spread across the healthcare system. For some reasons, the healthcare system's ability to adopt and accommodate the changes appears to happen slower than one would like (Berwick, 2003). More importantly, despite such advancements, packaging and delivery of treatment is often inefficient, ineffective, and consumer unfriendly (Herzlinger, 2006).

\section{IS Innovation always good?}

Healthcare is a broad field with a lot of opportunities that let us do a lot. New innovations can be exciting, but they can also be expensive and wasteful, if they have limited benefits. Introducing new interventions would be counter-productive at macro level if it is not as effective as first thought. Therefore, it does not have the value of addition and presentation with some risks in the shorter or longer terms. Decision makers often have to consider whether the 'new' is just a fad in order to balance the cost of a new warranted intervention or justify the effectiveness of the proposed innovation. There are numerous examples of new intervention programs with a lot of excitement without adequate evidence base such as percutaneous bladder neck suspension in female for stress urinary incontinence (Reid \& Parys, 2005) and use of laetrile for treating the cancer . There are other interventions that appeared to have high face validity but were later proved to be wrong; for instance, the use of human albumin in treatment of critically ill patients. There are other real reasons to be 
cautious before adopting and implementing new and creative ideas. The decision with regard to acceptability of a novel ideas, procedures or methods is often shaped by public opinions which is often the case for most investments in democratic societies. In the last decade, by developing the use of healthcare checklists in airlines to minimize human errors, checklists and scoring sheets came into vogue. Even though there was equivocal evidence for benefit of using early warning scores and rapid response teams for care of deteriorating patients, these are in widespread use (Davidoff, 2009). In New South Wales following the special commission of inquiry into acute care services, there was a surge of interest and concern about management of deteriorating patients that led to considerable additional investment (Garling, 2008). The question about opportunity cost, cost effectiveness, and value became the secondary concerns. Irrespective of actual benefit of implementing some recommendations, the political campaign train could not be stopped until the change in government. Not only the intervention is likely to effective, but also the cost-benefit analysis supports this investment. In other words, it is important to determine that the cost of shifting time, energy, and resources are more worthwhile than other priorities.

\section{Why Uptake of Innovation is not Fast Enough in Healthcare System}

There is no disagreement about the fact that public healthcare is a complex system. There are multiple forces that potentially influence and perhaps interfere with innovation such as influential stakeholders as providers and recipients of healthcare, government, bureaucracy, regulators and policy makers as potential inhibitors of innovation, complex interrelationships within the health care system, leadership that understands innovation, and culture.

\section{Influential Stakeholders - Providers and Recipients of Healthcare}

Influence of these stakeholders cannot be underestimated. In addition to healthcare professionals who have their own personal and professional needs (Huntington, Gilliam, \& Rosen, 2000), the health care system is full of administrators, pressure groups, patients with specific needs, lobby groups with their peculiar priorities, and many others who each may have self interest in having their needs and demands. As a result, bringing about a behavioral change to support innovation is always a challenge (Greco \& Eisenberg, 1993; Shortell, Bennett, \& Byck, 1998; Shortell, et al., 2001). To introduce and implement any innovation requires engagement of those likely to be affected by innovation (Heinelt $\&$ Smith, 2003). Implementing healthcare innovation always means full engagement of stakeholder groups including professionals who have to acquire the knowledge to introduce and implement innovation as well as consumers and careers which are directly affected by it. The problem is that these stakeholders may have divergent needs and also view what should be done and how.

\section{The Government}

Healthcare is a high stake game for the politicians and the government. It tends to touch the life of almost every citizen. For them every vote counts and any innovation or change does tend to bring with it more risk that some votes may be lost in the process. With every healthcare reform, there is a clear and sincere intention to be innovative (Arya, 2011).

\section{The Bureaucracy}

Most bureaucratic organizations benefit from stability, consistency, repetition, and following the policy. This ensures that there is less unpredictability, greater efficiency, and smooth operations which are all hallmarks of a well-running and managed bureaucratic system. On the other hand, innovation requires sources of novelty, change, adaptation, and experimentation. It has the potential to 
disturb the equilibrium, cause disruption in processes, and require readjustment of systems and processes.

\section{Regulators and Policy Makers as Potential Inhibitors of Innovation}

Policy makers and regulators are also key stakeholders in the healthcare system. Even though they do not necessarily possess specific healthcare expertise, they do influence how healthcare is delivered and to what extent. Not having technical expertise and with no ability to manage innovation, for them everything out of the ordinary is the potential risk. A drug innovative, method or procedure that has a potential to have a harmful effect or a side effect has to be anxiety provoking for them. In fact, the main task of bureaucrats and system managers is to eliminate special causes of variations. The entire function of quality control is focused on eliminating unwanted variability from the norm. Understandably, such an organizational system is not geared to take risks or promote innovation. It has also been argued that the public sector legislative and accountability frameworks results in riskaverse behaviors, and therefore may be a barrier to innovation. An innovation in the public service needs to consider risks around assessing whether legislation is required, the best legislative solution, consistency with other domestic and international laws, parliamentary and political risks, implementation risks, unintended consequences and unanticipated behavioral responses, potential legal challenges, reputational risks, complexity of ministerial, broader political, and community reactions and so on. Healthcare is also a service industry. There are more healthcare services than hospitality organizations that have a vision to serve and achieve excellence in delivery of healthcare services. Even though patients and their families are recipients of individualized care, collectively they do have a huge influence on where and how healthcare services might be delivered as well as what they expect to be their rights as recipients of public healthcare. This has required introduction of various laws and regulations to ensure consistency in healthcare provisions and to ensure that the recipients' expectations of healthcare system are met or not. Naturally, adoption of healthcare innovations in such a system is firmly regulated by laws and regulations to ensure the risks such as death, disability, and discomfort due to introduction of new products, processes or systems can be appropriately assessed before introducing new or innovative processes. This makes the rate of innovation process slower (Faulkner \& Kent, 2001).

\section{The Complex Interrelationships within the Healthcare System}

Implementing innovation requires understanding of the above system elements as these can allow or interfere with an innovation effort. Moreover, even though we talk about a healthcare system, provision of healthcare is a complicated business. Some broad guiding principles and policies can be applied to models of healthcare delivery; however, when it comes in implementation of a new initiatives or innovations, the health care system presents some unique considerations and challenges. Let's take an example of a potential innovative solution to the referral management system to move it from paper based to an electronic referral management system. Introduction of an electronic referral management system is considered as a new process for sending and receiving referrals, making decision about supporting tools to prioritize referrals, and providing a new system of notifying referrers and patients about the outcome of a referral. This would then require both the referrer as well as the receiving systems to interact differently. Individuals who have their own beliefs, instincts, experiences, freedom, power, influences, and personal and professional relationships that might be affected made implementing of innovation a complex process. Often such a structural change requires a change in the process, which in turn requires the players in the system to behave differently and adopt new ways of interacting with different parts of the system. On the other hand, there is huge 
scope and there are multiple opportunities for innovation. It also means that there is no simple recipe that can be picked up, used, replicated, and transported from one healthcare delivery system to another. Views, opinions, and perspectives of different stakeholders, customers, and providers within each individual system often determine what will be acceptable in their unique setting. Often these views and opinions are colored by their past experiences of change and innovation.

\section{Leadership that Understands Innovation}

It has been suggested that leadership is among the most important factors affecting innovation (Cummings \& O'Connell, 1978). Leaders or a leadership team in an innovative organization tend to have a very direct effect on the behavior of employees' creativity (Oldham \& Cummings, 1996) and motivation (Tierney, Farmer, \& Graen, 1999), often helping others to exhibit higher levels of creativity at work (Shin \& Zhou, 2003) and by establishing a supportive work environment for creativity (Amabile et al., 1996; Amabile, Schatzel, Moneta, \& Kramer, 2004; Scott \& Bruce, 1994). It is true that many new ideas can emerge from accidental or serendipitous events; however, occurring an innovation it is necessary to ensure that the process of nurturing that idea is systematically managed and developed. This requires some strategies, systems, processes, policies, and procedures to support the intended innovation, allocate the necessary resources, assess the results, and disseminate the knowledge. The effective leadership has to be all about developing such a strategy that is clearly articulated, readily understandable, and relevant to all levels within an organization. The possible strategy may need to focus on generating innovation inside and outside the organization (Egger \& Singh, 2009). In recent years, many healthcare systems have experimented with managerialism, market reforms, and a number of provider-purchaser arrangements. This could have resulted in some confusion between leadership, administration, and management components needed to lead an innovative healthcare system. Sometimes, technical and administrative leadership has become confusing if not always completely divergent.

\section{Culture}

Influence of culture in impeding or stimulating innovation must not be underestimated. Within a bureaucratic system like a public healthcare system, the need for a culture that allows organizations to be flexible and agile in accommodating and supporting the new ideas, invest necessary skills and resources, as well as respond to emerging needs and opportunities, seems to be essential to support innovation. A culture that recognizes encourages, and rewards new ideas and creativity can provide the right context for innovation occurrence. It is also true that innovation does not occur by chance. It must be planned, resourced, and managed. A well-functioning bureaucracy can in fact provide the necessary supportive framework for innovation to occur. Investment in building organizational capabilities to support innovation with appropriate trainings, equipments, information support systems, and other infrastructures is often necessary to facilitate innovation. A complex system like the public healthcare system that is often dependent on its effectiveness on other governmental systems; for instance, social support, education, housing, and employment also needs crossgovernment collaboration which leads to innovation.

\section{How to Drive Innovation The Innovation Recipe}

Like any recipe, the recipe itself cannot be considered as the sole reason for having a great dish. However, knowing what ingredients are needed and how to prepare the dish helps significantly. In broad terms, choosing a right leadership, creating the right environment, setting up an appropriate but different threshold setting, ensuring that people have technical expertise about outside world, and 
learning and developing a framework for occurring innovation consistently are all considered as important ingredients.

\section{The Environment}

A lot has been spoken about the need to create an environment for people to innovate. Many have mistakenly interpreted it as people's need to have a thinking time to come together, explore, and discuss new ideas. To encourage innovation, one proposal is that set aside the needed time to generate or develop an idea, test, and finally innovate. Virtually, this allocated time is not considered as thinking time, but it is a permission to innovate. The environment in which this permission is granted does not have to be stated in vision or mission statements. Indeed, for a high functioning organization, it is essential for usual businesses to consistently adopt themselves with efficiency measures and then test their errors or omissions. However, in addition to routine work, explicit encouragement, opportunity and space to innovate allows people to express their own ideas. Such an environment provides them protection to be bold and experiment and to the organization to explicitly and transparently set boundaries within which innovation would be allowed to occur. Allowing people to take lateral thinking and use their technical expertise help the emergence of new ideas. Developing a proper environment which gives permission for this to happen provides the greatest potential to emerge innovation.

\section{Innovation as a Part of Organizational Culture}

As noted above, most bureaucratic organizations tend to maintain status quo and have culture $\mathrm{s}$ that emphasize consistency, efficiency, and survival. Variability has the potential to introduce errors and inefficiencies. Signal insolvency, loss, and death can be the results of weak control. Regarding the innovation, it is considered as a part of organizational culture which can provide some protection against risk impacts, allow the organization to take calculated risks, and develop an appetite within the organization to be prepared for variability that may be produced in the process. Companies such as Apple, Toyota, and Cisco are considered as organizations that have made novelty as a consistent output of their organizations' culture.

\section{Task of Leadership is to Set the Appetite for Innovation}

A clear task for the leadership is to set the organization's appetite for innovation, be prepared to receive new ideas, and create an environment for these ideas to be tested. The test of the new idea should not be why it cannot be done, but how it can be done. Good thought leaders may not always be good implementers and good implementers may not be the best at marketing. The task of leaders is to understand strengths and weaknesses of players within the system bring together appropriate supports and encourage innovative ideas to evolve, grow and unfold.

\section{Don't Search for Innovators - Groom them}

A desire to employ people with light bulb lighting up ideas can be a long and unproductive trail. The belief that a progressive organization needs to search innovators and employ them to come up with ideas and innovations may not be a good strategy. Actually, innovations require good brains and most people have them. Greater success in innovations can be achieved through creating the right environment for people to come up with new ideas and breakthroughs. It is not about having thinkers in your organization or propagating the myth of the need for people to have 'thinking time'. Innovations can come from people's understanding and expertise of internal and external environment. Not all ideas are realistic and not all innovations are productive and value adding. 
Actually, some innovations or novel ideas happen one out of one hundred. Ideas can also take some time to develop, evolve, improve, and become deliverable. In other words, a rough pearl has to be refined, polished, and cut appropriately to become valuable one.

\section{Identifying an Opportunity}

It is inherent in all of us to strive and make things simpler, easier, and better. We do it all the time. In the healthcare environment, there are almost infinite opportunities for improvement. Gaps in service delivery, work flows, movement of staff, pathways of care, clinical guidelines, implementing evidence based interventions, confront us every day. From the most unskilled to the highly skilled specialists, all need opportunities for innovation in all aspects of healthcare delivery. These opportunities have to be identified, catalogued, understood, and agreed in order to provide impetus for innovations.

\section{Nurturing the Idea}

If an appropriate environment has been created in the organization, technical experts can propose good solutions. It may require them to access help and expertise of other experts, even enrolling people who they have no affiliation with. An infection control expert who believes she has an innovative idea about cleaning floors, might need input from people who know how cleaning is done (cleaners), what cleaning equipment modifications should be apply (engineers), what may be the most efficient cleaning cycle (system and process experts), the best antimicrobials to use for that environment (microbiologists), how it can be done on a mass scale e.g. across all floors of the large hospital (cleaning contractors), how to protect the intellectual property and develop a brand and so on. Laboratory ideas provide opportunities for growing and evolving new ideas.

\section{From Ideas to Fruition}

Often innovation comes from the mixing of ideas. New ideas can be converted into innovations. Many people within the organizations with good ideas struggle to convert their ideas into innovations because of real or perceived barriers that impede innovations. This requires not only a talk about abandoning status quo, but an explicit preparedness to support innovation, statement, and examples within the culture of the organization about the same. A willingness to tolerate other people's different thoughts and opinions, testing boundaries, and encouraging ideas is what leads to innovation.

\section{Innovation Risks Must be Managed}

An innovative or creative idea may not necessarily have a strong evidence base to support its effectiveness. One new idea may be half-baked, its implementation requires a new or different process rather than the available one within the organizational system, and no available prediction or accurate forecast ensures its success. Therefore, it is necessary to assess beforehand any possible potential hazards or risks, managed, and controlled them. Implementation may also require a risk management planning which includes contemporaneous collection of necessary data and information to analyze continuously its effectiveness and achievement against agreed objectives.

\section{Evaluate}

Reichle (2006) suggested a method for assessing the innovative product ideas and products. This method can be used to measure the degree of innovation or the grade of innovations' novelty as well as the products' potential success. The evaluation method is based on the quality function deployment (QFD) method with additional factors or indices included; for instance, the importance of novelty of the customer and product requirements, relevant aspects of the manufacturer benefit of a new product. 
In evaluating an innovation, it may be useful to evaluate success of the product and/or an idea from different perspectives or domains. However, it is important not to become preoccupied with scoring these domains or trying to achieve a high cumulative score on each domain to determine the success of innovation. The domain of interest must be determined by the kind of innovation goal that they aspired.

\section{Continuously Consider What the Customer may Want in the Future}

Many innovations are introduced to gain competitive advantage by attracting customers to the product or the service. However, it is important to be aware of the fact that customers tend to express their current preferences. An innovative idea or product is often pitched to anticipate future needs and demands and even to alter and change the customers' preferences and generate or shape the needs and demands in the future. Indeed, the risk of focusing too much on current customers' needs is well recognized (Balachandra \& Friar, 1997; Van der Panne, Van der Beer, \& Kleinknec, 2003). A new product, idea, or service may allow its manufacturing company to gain a competitive edge over another product or service by increasing productivity, quality, and cost benefit for both producer and consumer, adding new properties or functions by getting a better market fit than other products or services. However, complexities of markets, consumer attitudes, and behaviors would tend to suggest that neither of these can be considered to be absolute or even absolutely relevant. For example, even if an innovation is able to increase the quality of a performance, it may give no competitive advantage as customers often have difficulties in recognizing the performance of different products correctly (Balachandra \& Friar, 1997). New functions or properties of an innovation may seem interesting for customers even if it has some unimportant aspects which are considered unnoticeable. One new product may have a good fit with the social, religious of other characteristics of one market and equally adverse effects on other one. Advantages gain from innovations are often short-lived as competitors may be able to introduce and implement those innovations within a short space of time.

\section{Conclusion}

Mostly, innovation in one situation is considered as an adaptation of a solution that has been tried and experimented elsewhere. There are many essential ingredients for innovation to occur which two of them are particularly important including opportunity and reason. Innovations come when there is an issue which needs to be resolved. This reason can be a competition, crisis, or financial, socio-political, cultural, or clinical problem. However, knowing what needs to be done and actually do it can be considered real challenges because there is a big difference between an idea and an innovation. Perhaps the challenge to implement new ideas in public healthcare systems is considerable with regard to existing complexities and bureaucratic systems for managing potential risks and stakeholders' power which interfere with the desire or ability to innovate. Clearly, the healthcare system has often struggled to even take advantage of technological advancements that are easily available and accessible in other sectors. For example, electronic healthcare records have been just round the corner and patient controlled healthcare records have sophisticated and secure systems to make the electronic health records available and accessible to patients. Even though there are some very sophisticated logistical solutions available in other industries, patients continue to wait hours in emergency departments in long surgery waiting lists. As far as healthcare systems are concerned, the system-wide challenges try to meet the demands which continue to increase steadily, manage community expectations from the public purse irrespective of whether it supports effectiveness, safe care, clinical care provision, access or equity, and how to support rising expenditure due to technological advancements. Perhaps as The concepts of competition, survival, and change-agent 
leadership are not appropriate for public service. Instead, emphasis is, and should be, on the preservation of public order and the reliable and predictable provision of public services. Organisations with an intention to drive innovation projects must pay particular attention to creating an appropriate environment and culture that fosters innovation and provides leadership that sets an organization's appetite to identify, nurture, and implement innovation as well as managing risks that a new idea may encounter.

\section{References}

Amabile, T. M. (1983). The social psychology of creativity. New York: Springer Verlag.

Amabile, T. M. (1998). How to kill creativity. Harvard Business Review, 76(5), 77-87.

Amabile, T. M., Conti, R., Coon, H., Lazenby, J., \& Herron, M. (1996). Assessing the work environment for creativity. Academy of Management Journal, 39(5), 1154- 1184.

Amabile, T. M, Schatzel, E. A, Moneta, G. B, \& Kramer, S. J. (2004). Leader behaviors and the work environment for creativity: Perceived leader support. The Leadership Quarterly, 15(1), 5-32.

Arya, D. K. (2011). Time to salvage national health and hospital reform: At least some of it! Asia Pacific Journal of Health Management, 6(1), 19-22.

Balachandra, R, \& Friar, J. H. (1997). Factors for success in R\&D projects and new product innovation: A contextual framework. IEEE Transactions on Engineering Management, 44(3), 276-287.

Berwick, D. M. (2003). Disseminating innovations in health care. JAMA, 289(15), 1969-1975.

Christenson, C. M, Anthony, S. D, \& Roth, E. A. (2004). Seeing what's next: using the theories of innovation to predict industry change (Vol. 293). Boston: Harvard Business School Press.

Coelho, D. A., \& Matias, J. C. O. (2010). An empirical study on integration of the innovation management systems (MS) with other MSs within organisations. Proceedings of ERIMA, Wiesbaden, Germany.

Cummings, L. L., \& O’Connell, M. J. (1978). Organizational Innovation: A model and needed research. Journal of Business Research, 6(1), 33-50.

Davenport, T. H., Leibold, M., \& Voelpel, S. (2006). Strategic management in the innovation economy: Strategic approaches and tools for dynamic innovation. Erlangen: Publicis Corporate Publishing and Wiley-VCH Verlag GmBH.

Davidoff, F. (2009). Heterogeneity is not always noise: Lessons from improvement. JAMA, 302(23), 2580-2586.

Egger, W. D, \& Singh, S. K. (2009). The Public innovator's playbook: Nurturing bold ideas in government. Washington, DC: Deloitte Research \& the Ash Institute for Democratic Goveranance and Innovation, Harvard Kennedy School of Government.

Fagerberg, J., Mowery, D. C., \& Nelson, R. R. (2005). The Oxford handbook of innovation. Oxford: Oxford University Press.

Faulkner, A., \& Kent, J. (2001). Innovation and regulation in human implant technologies: Developing comparative approaches. Social Science \& Medicine, 53, 895-913.

Garling, P. (2008). Final report of the special commission of inquiry: Acute care services in NSW public hospitals. Sydney: NSW Government.

Greco, P. J., \& Eisenberg, J. M. (1993). Changing physicians' practices. New England Journal of Medicine, 329(17), 12711273.

Hage, J., \& Hollingsworth, R. A. (2000). A strategy for analysis of idea innovation networks and institutions. Organizational Studies, 21(5), 971-1004.

Hamel, G. (2000). Leading the revolution. Boston, MA: Harvard Business School Press.

Heinelt, H, \& Smith, R. (2003). Sustainability, innovation, and participatory governance: A cross national study of the EU eco-management and audit scheme. Aldershot, UK: Ashgate Publishing.

Herzlinger, R. E. (2006). Why innovation in health care is so hard. Harvard Business Review, 84(5),58-66.

Huntington, J, Gilliam, S, \& Rosen, R. (2000). Organizational development for cinical governance. British Medical Journal, $16,679-682$.

Lansisalmi, H., Kivimaki, M., Aalto, P., \& Ruoranen, R. (2006). Innovation in healthcare: A systematic review of recent research. Nursing Science Quarterly,19(1), 66-72. 
McGlynn, E. A., Asch, S. M., Adams, J., Keesey, J., Hicks, J., DeCristofaro, A., \& Kerr, E. A. (2003). The quality of health care delivered to adults in the United States. New England Journal of Medicine, 348(26), 2635-2645.

Moore, G. A. (2004). Darwin and the demon: Innovating within established enterprises. Harvard Business Review, 82(7/8), 86-92.

Oldham, G. R, \& Cummings, A. (1996). Employee creativity: Personal and contextual factors at work. Academy of Management Journal, 39(3), 607-634.

Reichle, M. (2006). Bewertungsverfahren zur Bestimmung des Erfolgspotenzials und des Innovationsgrades von Produktideen und Produkten(Unpublic doctoral dissertation). Universität Stuttgart, Institut für Konstruktionstechnik und Technisches Design, Stuttgart.

Reid, S. V., \& Parys, B. O. T. (2005). Long tern 5-year followup of the results of the vesica procedure. Journal of Urology, 173, 1234-1236.

Scott, S. G., \& Bruce, R. A. (1994). Determinants of innovative behavior: A path model of individual innovation in the workplace. Academy of Management Journal, 37(3), 580-607.

Shin, S. J, \& Zhou, J. (2003). Transformational leadership, conservation and creativity: Evidence from Korea. Academy of Management Journal, 46(6), 703-714.

Shortell, S. M., Bennett, C. L., \& Byck, G. R. (1998). Assessing the impact of continuous quality improvement on clinical practice: What it will take to accelerate progress. Milbank Quarterly, 76(4), 593-624.

Shortell, S. M., Zazzali, J. I., Burns, L. R., Alexander, J. A., Gillies, R. R., Budetti, P. P., Waters, T. M., \& Zuckerman, H. S. (2001). Implementing evidence-based medicine: The role of market pressures, compansation, incentives, and culture in physican organizations. Medical Care, 39, 62-78.

Sumii, K. (1986). Innovation management. Tokyo: Japan Economics Newspaper Press.

Tierney, P., Farmer, S. M, \& Graen, G. B. (1999). An examination of leadership and employee creativity: The relevance of traits and relationships. Personnel Psychology, 52(3), 591-620.

Van der Panne, G., Van der Beer, S., \& Kleinknec, H. A. (2003). Success and failure of innovation: Literature review. International Journal of Innovation Management, 7(3), 309-339.

Varkey, P. A., Horne, A., \& Bennet, K. E. (2008). Innovation in health care: A primer. American Journal of Medical Quality, 23(5), 382-388.

West, M. A. (1990). The social psychology of innovation in groups. In M. A.West, \& J. L. Farr (Ed.), Innovation and creativity at work: Psychological and organizational strategies (pp. 309-334). Chichester, UK: Wiley.

Woodman, R. W., Sawyer, J. E., \& Griffin, R. W. (1993). Toward a theory of organizational creativity. Academy of Management Review, 18(2), 293-321.

Zaltman, G., Duncan, R., \& Holbek, J. (1973). Innovation and organizations. New York, NY: Wiley. 